\title{
Urease: Occurrence, inhibition and immobilization
}

\section{Sandeep Kumar}

${ }^{1}$ Department of Biochemistry and Physiology, College of Biotechnology, Sardar Vallabhbhai Patel University of Agriculture \& Technology, Meerut (UP), India.

E-mail: sandeep4554@gmail.com

\section{Abstract}

Urease (Urea amidohydrolase; EC 3.5.1.5) was the first enzyme to be crystallized. Urease is an important enzyme present in many organisms, including plants. This enzyme plays diverse roles and mainly involved in the nitrogen metabolism. The bacterial urease has been extensively studied may be due to the simplicity of system and its significance in various pathological conditions and role in agriculture etc. Jack bean urease was the first nickel-containing enzyme to be described and it is the only nickel-containing metalloenzyme identified so far in plants. Its rapid catalysis for the hydrolysis of urea to ammonia and carbon dioxide plays an essential role in agriculture and human health. In most of the industrial, analytical, and clinical processes, enzymes are mixed in a solution with substrates and cannot be economically recovered after the exhaustion of the substrates. By mimicking the natural mode of occurrence in living cells, where enzymes for the most cases are attached to cellular membranes, the systems stabilize the structure of enzymes, hence their activities. Thus, as compared to free enzymes in solution immobilized enzymes are more robust and more resistant to environmental changes. More importantly, the heterogeneity of the immobilized enzyme systems allows easy recovery of enzyme and product, multiple reuses of enzymes, continuous operation of enzymatic processes, rapid termination of reactions and greater variety of bioreactor designs.

Keywords: urease, inhibition, immobilization, hydrogels, urea

Paper cited: Kumar, S. (2016). Urease: Occurrence, inhibition and immobilization. South Asian Journal of Food Technology and Environment, 2(3\&4): 418-431.

\section{Introduction}

In bacteria, the enzyme urease, as in other species, catalyzes the hydrolysis of urea. Urea hydrolysis in most bacteria is used as a nitrogen or carbon source for anabolic processes. However, in gastric tract-dwelling bacteria and other bacteria that encounter acid during their life cycles, urea hydrolysis contributes to their ability to survive in acid. Moreover, in gastric tract-dwelling bacteria, this process confers on them the unique ability to colonize the stomach. Although urea is the major substrate of urease, this enzyme is capable of hydrolyzing (albeit poorly) other substrates such as acetamide, formamide, $\mathrm{N}$-methylurea, semicarbazide, and hydroxyurea (Dixon et al., 1980). Bacterial ureases have been shown to be important virulence determinants in the pathogenesis of many clinical conditions in human and animals. Urease is directly involved in the formation of infection stones and contributes to the pathogenesis of urolithiasis, pyelonephritis, ammonia and hepatic encephalopathy, hepatic coma and urinary catheter encrustation. Urease is known to be the major cause of pathologies induced by Helicobacter pyroli, which allows this pathogen to survive at the low $\mathrm{pH}$ of the stomach during colonization and therefore plays an important role in the pathogenesis of gastric and peptic ulcers, which in some cases may progress to cancer (Mobley et al., 1995). In agriculture, high urease activity causes significant environmental and economic problems by releasing abnormally large amounts of ammonia 
into the atmosphere during urea fertilization (Mobley and Hausinger, 1989; Mobley et al., 1995; Sirko and Brodzik, 2000).

\section{Occurrence and Role of Urease}

Many organisms, including plants, some bacteria, fungi and invertebrates, synthesize urease. Urease is a cytosolic enzyme. In most of the studied cases the majority of its activity is associated with the soluble fractions of the cells (Mobley et al., 1995). Many species of leguminosae have high levels of urease activity in their seeds. Whereas in mammals urea is a non-toxic waste form for excess ammonia, in plants significant quantities of nitrogen flow through urea (urea is $47 \%$ nitrogen), which can be recycled only by urease action (Polacco and Holland, 1993; Sirko and Brodzik, 2000). Urease activity was found in several species of fungi. Biochemically, the best-characterized plant urease is that from jack bean (Takishima et al., 1988; Riddles et al., 1991; Hirai et al., 1993; Karmali and Domingos, 1993). Urease from mulberry (Morus alba) leaves has also been purified and characterized (Hirayama et al., 2000).

The best genetic data concerning plant ureases are available for soybean (Polacco and Holland, 1993; 1994). There are at least three key enzymes involved in urea metabolism in plants: arginase, urease and glutamine synthetase. The primary role of ureases is to allow the organism to use external or internally generated urea as a nitrogen source (Mobley and Hausinger, 1989; Mobley et al., 1995). Significant amounts of plant nitrogen flow through urea. This compound derives from arginine and possibly from degradation of purines and ureides (Polacco and Holland, 1994). The nitrogen present in urea is unavailable to the plant unless hydrolyzed by urease. The product of urease activity ammonia - is incorporated into organic compounds mainly by glutamine synthetase.

It has been reported that overexpression of the pine glutamine synthetase in transgenic poplar improves the growth of the plants, probably by increasing the efficiency of nitrogen utilization (Gallardo et al., 1999). On the other hand, it has been shown that increased activity of this enzyme in the roots of a legume plant, Lotus japonicus, leads to decreased plant biomass production, possibly due to limited nitrate uptake (Limami et al., 1999). These results, which seem contradictory at first glance, might reflect the different roles of glutamine synthetase isoenzymes in different plants and/or different plant organs. They indicate the significance of this enzyme for plant nitrogen metabolism. The activity of glutamine synthetase, the amount of its product, glutamine, and possibly the availability of its substrate, ammonia, seem to be important factors controlling nitrogen metabolism and affecting plant growth (Stitt, 1999; Wiren et al., 2000). Carlini and Guimarães (1981) isolated canatoxin, a highly toxic protein from jack beans that induces convulsions and death in mice and rats when injected intraperitoneally.

Canatoxin was subsequently identified as an isoform of urease (Follmer et al., 2001) which can be isolated separately from jack bean urease using their different affinities for metal ions (Follmer et al., 2004). Ureases from plant and microbial sources belong to a group of multifunctional proteins displaying not only the capacity for ureolysis, but also toxic effects in insects. The newly described properties of plant ureases may shed new light on the physiological roles of these proteins in the source organisms, reinforcing the possibility of plant ureases having a protective role against phytopathogens through an entirely different mechanism, unrelated to the release of ammonia. Microbial ureases are important enzymes in certain human and animal pathogenic states, in ruminant metabolism, and in environmental transformations of certain nitrogenous compounds.

Urease activity plays a central role in the pathogenesis elicited by a number of bacterial species. This enzyme plays an 
important role in the pathological conditions like, urolithiasis (stone formation), catheter encrustation, pyelonephritis, ammonia encephalopathy, hepatic encephalopathy, hepatic coma, and inactivation of complement etc. In humans, P. mirabilis is the most common organism implicated in stone formation (Rosenstein, 1986). Microbial ureases play an important role in the nitrogen metabolism of ruminants such as cattle, sheep, and other animals that contain a forestomach (Huntington, 1986). Substantial amounts of animal-derived urea are recycled to the rumen, where ureolytic activity releases ammonia, the major source of nitrogen for most ruminal bacteria (Bryant, 1959). The microbial biomass generated is then utilized as a nutrient by the ruminant. Urease activity is widely distributed in soil and aquatic environments, where it plays an essential role in nitrogen metabolism (Bremner and Mulvaney, 1978). For example, degradative processes involving protein and nucleotide turnover require urease activity. More importantly, effective urea fertilization requires controlled ureolysis to enhance efficiency and minimize crop damage. The availability of fixed nitrogen is the major limitation to agricultural productivity.

Two major forms of fixed nitrogen in the environment are proteins and polynucleotides. These components are hydrolyzed to the amino acid and nucleotide monomers and then further degraded by a variety of enzymes. The guanidino group of arginine and the ring nitrogens of purines are released as urea, which is further hydrolyzed by urease (Varner, 1959; Vogels and vander Drift, 1976). The product ammonia can be taken up and utilized by soil microbes and plants. However, in many environments the level of available nitrogen compounds is inadequate for optimal crop production. Therefore, fertilizers are applied which can be converted to a form of nitrogen that plants can assimilate. Urea is widely used because of its low cost, ease in handling, and high nitrogen content (Beaton, 1978). Ureaplasma species differ from all other mycoplasmas (class Mollicutes) by possessing urease activity (Taylor-Robinson and Gourlay, 1984). Urea hydrolysis appears to play a major role in the energy metabolism of ureaplasmas by promoting ATP synthesis through a chemiosmotic mechanism (Masover et al., 1977a,b; Romano et al., 1980; 1986). This rather unique energy-yielding mechanism is essential for the ureaplasmas, which are known to lack the major energy-yielding (glycolytic and arginine dihydrolase) pathways established so far for other mollicutes (Pollack, 1986).

\section{Urease Inhibitors}

One of the most pressing environmental issues confronting agriculture is the loss of soil nitrogen, derived from either fertilizer nitrogen or symbiotic nitrogen fixation by legumes, to the atmosphere as gases $\left(\mathrm{NH}_{3}, \mathrm{~N}_{2}\right.$ and $\mathrm{N}_{2} \mathrm{O}$, the latter being a potent greenhouse gas) or to groundwater via leaching as $\mathrm{NO}_{3}^{-}$. These losses of nitrogen not only decrease nitrogen-use efficiency, and therefore have economic implications, but just as importantly, impact on groundwater quality and contribute to greenhouse gas emissions. The nitrification and urease inhibitors can be successfully used as tools to manage these losses. Studies on inhibitors are useful to learn about how enzymes interact with their substrates; role of inhibitors in enzyme regulation; drugs if they inhibit aberrant biochemical reactions; understanding the role of biological toxins; insecticides etc (Kumar and Kayastha, 2010a; 2010b; 2010c; Kumar and Kayastha, 2012; Kumar, 2015; Lehari et al., 2015; Kumar, 2016). Ammonium, present in soil is derived from several sources: directly from the mineralization of organic matter and the addition of ammoniumcontaining fertilizers, and, indirectly, as the result of the hydrolysis of applied urine and fertilizer urea. Under typical conditions ammonium is oxidized first to nitrite and then to nitrate $\left(\mathrm{NO}_{3}^{-}\right)$by bacteria (nitrification).

Plants can utilize both ammonium and nitrate. Furthermore, under anaerobic conditions 


\section{Sandeep Kumar}

$\mathrm{NO}_{3}{ }^{-}$nitrogen can be reduced by denitrifying bacteria to the gases $\mathrm{N}_{2} \mathrm{O}$ and $\mathrm{N}_{2}$ (denitrification). These gases can also be produced from ammonia and nitrite under aerobic conditions by chemical reactionschemodenitrification. For these reasons, controlling the processes of nitrification and/or urease hydrolysis are, theoretically at least, potential tools to restrict nitrogen leaching, greenhouse gas emissions and ammonia volatilization from soils. As a consequence the nitrogen cycle should be more efficient and nitrogen use efficiency increased. It has focused therefore on the use of nitrification inhibitors in conjunction with fertilizer nitrogen and animal wastes, and urease inhibitors applied with ureabased fertilizer. Urease inhibitors restrict the conversion of urea and urine to ammonium, and hence to nitrate, in soils.

The majority of the research indicates that nitrification inhibitors, when applied to soils in conjunction with nitrogen fertilizers or animal wastes, have beneficial effects on reducing nitrate leaching and nitrous oxide emissions, and, as a result increase plant growth (Stelly, 1980; Williamson et al., 1998; Merino et al., 2002). The high affinity of ureases for metal ions (e.g. $\mathrm{Hg}^{2+}, \mathrm{Cu}^{2+}, \mathrm{Ni}^{2+}$ and $\mathrm{Zn}^{2+}$ ) as well as their inhibitory effects (Hughes et al., 1969) upon the ureolytic and insecticidal activities of the enzyme raises the possibility of metals being modulators of urease activities. Follmer and Carlini (2005) suggested that jack bean urease aggregation could be induced by binding of metal. The $\mathrm{Cu}^{2+}$ induced polymeric forms of jack bean urease have no urease or insecticidal activities, similar to aggregated forms of jack bean urease induced by freezing and thawing cycles (Follmer et al., 2004). Chemical modification of histidine residues of jack bean urease by treatment with diethylpyrocarbonate decreases its affinity for $\mathrm{Cu}^{2+}$ and inhibits oligomerization induced by this metal, resulting in a protection of insecticidal properties of jack bean urease from the inactivation by $\mathrm{Cu}^{2+}$ (Follmer and Carlini, 2005). In addition, it was shown that certain ions, notably $\mathrm{Hg}^{2+}$ and $\mathrm{Cu}^{2+}$ are inhibitors of urease activity, and it was suggested that this inhibition might involve blockage of thiol groups in the protein (Hughes et al., 1969). $\mathrm{Cu}^{2+}$ can bind to many sites on the $K$. aerogenes urease in addition to the usual metallocenter, but most of the adventitious metal is removed by treatment with EDTA (Yamaguchi et al., 1999).

Several studies hypothesized that nonproductive metal binding arises by coordination to $\mathrm{Cys}^{319}$ localized in the mobile flap of $K$. aerogenes urease (Martin and Hausinger, 1992; Pearson et al., 1997). On the other hand, Yamaguchi et al., (1999) reported that the mutation $\mathrm{Cys}^{319 \mathrm{~A}}$ does not prevent the irreversible inactivation of the enzyme by $\mathrm{Cu}^{2+}$, suggesting that an affect other than blockage of thiol is involved. $\mathrm{Cys}^{319}$ in $K$. aerogenes urease is located at the active site (in $K$. aerogenes urease, the sulfur atom is positioned 6.7 and 6.1 $\AA$ from Ni-1 and Ni-2, respectively) (Martin and Hausinger, 1992; Pearson et al., 1997) and is surprisingly conserved in the amino acid sequences of both microbial and plant ureases. In addition, due to its reactivity, this cysteine is one of the most important targets for urease inhibition (Todd and Hausinger, 1991; Pearson et al., 1997; Zhang et al., 2006; Krajewska et al., 2004).

\section{Urease Immobilization}

Enzymes may be immobilized by a variety of methods, which may be broadly classified as physical, where weak interactions between support and enzyme exist, and chemical, where covalent bonds are formed with the enzyme (Kennedy and Cabral, 1983; Bullock, 1995;). To the physical methods belong: (i) containment of an enzyme within a membrane reactor, (ii) adsorption (physical, ionic) on a water-insoluble matrix, (iii) inclusion (or gel entrapment), (iv) microencapsulation with a solid membrane, (v) microencapsulation with a liquid membrane, and (vi) formation of enzymatic Langmuir-Blodgett films. The chemical immobilization methods include: (i) 
covalent attachment to a water-insoluble matrix, (ii) cross-linking with use of a multifunctional, low molecular weight reagent, and (iii) co-crosslinking with other neutral substances, e.g. proteins. Urease has been immobilized on a variety of carriers such as on starch, alginate, silica, chitosan or agarose (Kumar et al., 2005; Kumar et al., 2009; Swati et al., 2007).

Numerous other methods which are combinations of the ones listed or original and specific of a given support or enzyme have been devised. However, no single method and support is best for all enzymes and their applications. This is because of the widely different chemical characteristics and composition of enzymes, the different properties of substrates and products, and the different uses to which the product can be applied. Besides, all of the methods present advantages and drawbacks. Adsorption is simple, cheap and effective but frequently reversible, covalent attachment and crosslinking are effective and durable, but expensive and easily worsening the enzyme performance, and in membrane reactor-confinement, entrapment and microencapsulations diffusional problems are inherent. Consequently, as a rule the optimal immobilization conditions for a chosen enzyme and its application are found empirically by a process of trial and error in a way to ensure the highest possible retention of activity of the enzyme, its operational stability and durability.

This immobilization on a variety of carriers is well documented in the literature: There is adsorption on raw starch (Ray et al., 1994), entrapment in alginate (Kokufuta et al., 1988), immobilization on ion exchanger (Roy and Hedge, 1987), silica beds (Germain and Crichton, 1980), porous chitosan (Obha et al., 1979) or agarose (Sheffield et al., 1995). To date, several immobilized enzyme-based processes have proved economic and have been implemented on a larger scale, mainly in the food industry, where they replace free enzymecatalyzed processes, and in the manufacture of fine specialty chemicals and pharmaceuticals, particularly where asymmetric synthesis or resolution of enantiomers to produce optically pure products are involved (Kennedy and Cabral, 1983; Bullock, 1995). The scale of the processes ranges from about $10^{6}$ tons per year for high-fructose corn syrup, arguably one of the most commercially important immobilized enzyme-based processes, to about $10^{2}$ tons per year for enantiopure L-DOPA (van de Velde et al., 2002). Immobilization on a conducting matrix (e.g., a metal electrode) is generally difficult but is desirable in biosensor application. Several enzyme biosensors have been designed and constructed using various kinds of immobilization techniques. Works dealing with chemically modified electrodes have made possible the permanent chemical modification of various electrode materials (Watkins et al., 1975). For example, gold electrodes have been covalently modified using thiol compounds (Katz et al., 1997).

Glassy carbon is not an attractive material for enzyme immobilization as its chemical inertness towards coupling reagents is very high. Enzyme adsorptions on graphite or activated carbon followed by glutaraldehyde (Liu et al., 1975) or soluble carbodiimide (Cho and Bailey, 1977; 1979) cross-linking have been reported. Covalent immobilization of the glucose oxidase enzyme onto graphite powder by carbodiimide treatment was reported (Gorton, 1995). The direct covalent binding of the enzyme by carbodiimide coupling onto glassy carbon after initial activation by electrochemical oxidation was reported by Bourdillon et al. (1980).

Immobilization on Hydrogels: Hydrogels are superabsorbent (they can contain over $99 \%$ water) natural or synthetic polymers. Hydrogel is a network of polymer chains that are waterinsoluble, sometimes found as a colloidal gel in which water is the dispersion medium. Gelling agents are materials used to thicken and stabilize liquid solutions, emulsions, and suspensions. They dissolve in the liquid phase as a colloid mixture that forms an internal structure giving 


\section{Sandeep Kumar}

the resulting gel an appearance of a solid matter, while being mostly composed of a liquid.

Typical gelling agents include natural gums, starches, pectins, agar-agar and gelatine. Often they are based on polysaccharides or proteins. Examples include alginic acid, sodium alginate, potassium alginate, calcium alginate (polysaccharides from brown algae); agar (a polysaccharide obtained from red seaweeds); carrageenan (a polysaccharide obtained from red seaweeds); locust bean gum (a natural gum from the seeds of the Carob tree); pectin (a polysaccharide obtained from apple or citrusfruit); gelatine (made by partial hydrolysis of animal collagen).

Calcium alginate is just as widely used as polyacrylamide. Unlike polyacrylamide gels, gelation of calcium alginate does not depend on the formation of more permanent covalent bonds between polymer chains. Rather, polymer molecules are cross-linked by calcium ions. Because of this, calcium alginate beads can be formed in extremely mild conditions, which ensure that enzyme activity yields of over $70 \%$ can be routinely achieved. However, just as easily as calcium ions can be exchanged for sodium ions, they can also be displaced by other ions. This property can both be advantageous and disadvantageous. If needed, enzymes or microbial cells can be easily recovered by dissolving the gel in a sodium solution. On the other hand, proper caution must be exercised to ensure that the substrate solution does not contain high concentrations of those ions that can disintegrate the gel.

Alginate, commercially available as alginic acid, sodium salt, commonly called sodium alginate, is a linear polysaccharide normally isolated from many strains of marine brown seaweed and algae, thus the name alginate. The copolymer consists of two uronic acids: D-mannuronic acid (M) and L-guluronic acid $(\mathrm{G})$. Because it is the skeletal component of the algae it has the nice property of being strong and yet flexible. Alginic acid can be either water soluble or insoluble depending on the type of the associated salt. The salts of sodium, other alkali metals, and ammonia are soluble, whereas the salts of polyvalent cations, e.g., calcium, are water insoluble, with the exception of magnesium. Polyvalent cations bind to the polymer whenever there are two neighboring guluronic acid residues. Thus, polyvalent cations are responsible for the cross-linking of both different polymer molecules and different parts of the same polymer chain. The process of gelation, simply the exchange of calcium ions for sodium ions, is carried out under relatively mild conditions. Because the method is based on the availability of guluronic acid residues, which will not vary once given a batch of the alginate, the molecular permeability does not depend on the immobilization conditions. Rather, the pore size is controlled by the choice of the starting material. The ionically linked gel structure is thermostable over the range of $0-100{ }^{\circ} \mathrm{C}$; therefore heating will not liquefy the gel.

However, the gel can be easily redissolved by immersing the alginate gel in a solution containing a high concentration of sodium, potassium, or magnesium. Maintaining sodium: calcium $\leq 25: 1$ will help avoid gel destabilization. In fact, it is recommended by alginate vendors to include $3 \mathrm{mM}$ calcium ions in the substrate medium. On the other hand, citrate or phosphate $\mathrm{pH}$ buffers cannot be effectively used without destabilizing the alginate gel. Alginate is currently widely used in food, pharmaceutical, textile, and paper products. The properties of alginate utilized in these products are thickening, stabilizing, gelforming, and film-forming. Alginate polymers isolated from different alginate sources vary in properties. Different algae, or for that matter different part of the same algae, yield alginate of different monomer composition and arrangement. There may be sections of homopolymeric blocks of only one type of monomer (-M-M-M-) (-G-G-G-), or there may be sections of alternating monomers (-M-G-MG-M-). 


\section{Urease: Occurrence, inhibition and immobilization}

Different types of alginate are selected for each application on the basis of the molecular weight and the relative composition of mannuronic and guluronic acids. For example, the thickening function (viscosity property) depends mainly on the molecular weight of the polymer; whereas, gelation (affinity for cation) is closely related to the guluronic acid content. Thus, high guluronic acid content results in a stronger gel. The enzyme-immobilization by entrapment using an alginate gel is fast, mild and low-cost, and this method is used with a wide range of biocatalysts. However, the matrix has some disadvantages because alginate gel is hydrophilic and dissolves in highly concentrated electrolyte and phosphate buffer solutions. The gel network is so soft that a low molecular weight enzyme such as protease leaks out of the gel network.

Chitin and chitosan are natural polyaminosaccharides (Hudson and Smith, 1998), chitin being one of the world's most plentiful, renewable organic resources. A major constituent of the shells of crustaceans, the exoskeletons of insects and the cell walls of fungi where it provides strength and stability. Chemically, chitin is composed of $\beta(1 \rightarrow 4)$ linked 2-acetamido-2-deoxy- $\beta$-D-glucose units (or $N$-acetyl-D-glucosamine) (Peter, 1995), forming a long chain linear polymer. It is insoluble in most solvents. Chitosan, the principal derivative of chitin, is obtained by $\mathrm{N}$ deacetylation to a varying extent that is characterized by the degree of deacetylation, and is consequently a copolymer of $N$-acetyl-Dglucosamine and D-glucosamine.

Chitin and chitosan can be chemically considered as analogues of cellulose, in which the hydroxyl at carbon- 2 has been replaced by acetamido and amino groups, respectively. Chitosan is insoluble in water, but the presence of amino groups renders it soluble in acidic solutions below $\mathrm{pH}$ about 6.5. It is important to note that chitin and chitosan are not single chemical entities, but vary in composition depending on the origin mid manufacture process. Chitosan can be defined as chitin sufficiently deacetylated to form soluble amine salts, the degree of deacetylation necessary to obtain a soluble product being $80-85 \%$ or higher. Commercially, chitin and chitosan are obtained at a relatively low cost from shells of shellfish (mainly crabs, shrimps, lobsters and krills), wastes of the seafood processing industry (Hudson and Smith, 1998). Basically, the process consists of deproteinization of the raw shell material with a dilute $\mathrm{NaOH}$ solution and decalcification with a dilute HC1 solution. To result in chitosan, the obtained chitin is subjected to $N$-deacetylation by treatment with a $40-45 \% \mathrm{NaOH}$ solution, followed by purification procedures. Chitosan possesses distinct chemical and biological properties (Hudson and Smith, 1998). In its linear polyglucosamine chains of high molecular weight, chitosan has reactive amino acid hydroxyl groups, amenable to chemical modifications (Peter, 1995; Kurita, 2001; Dutta et al., 2002). Additionally, amino groups make chitosan a cationic polyelectrolyte $\left(p K_{a} \approx 6.5\right)$, one of the few found in nature. This basicity gives chitosan singular properties: chitosan is soluble in aqueous acidic media at $\mathrm{pH}<6.5$ and when dissolved possesses high positive charge on $-\mathrm{NH}_{3}{ }^{+}$groups, it adheres to negatively charged surfaces, it aggregates with polyanionic compounds, and chelates heavy metal ions. Both the solubility in acidic solutions and aggregation with polyanions impart chitosan with excellent gel-forming properties. Along with unique biological properties that include biocompatibility, biodegradability to harmless products, non-toxicity, physiological inertness, remarkable affinity to proteins, hemostatic, fungistatic, antitumoral and anticholesteremic properties, chitin and chitosan, as yet underutilized, offer an extraordinary potential in a broad spectrum of applications, which are predicted to grow rapidly once the standardized chitinous materials become available. Crucially, as bio- and biodegradable polymers 
chitin/chitosan materials is eco-friendly, safe for humans and the natural environment.

As enzyme immobilization supports chitin- and chitosan based materials are used in the form of powders, flakes and gels of different geometrical configurations. Preparation of chitosan gels is promoted by the fact that chitosan dissolves readily in dilute solutions of most organic acids, including formic, acetic, tartaric and citric acids, to form viscous solutions that precipitate upon an increase in $\mathrm{pH}$ and by formation of water-insoluble ionotropic complexes with anionic polyelectrolytes. In this way chitosan gels in the form of beads, membranes, coatings, capsules, fibers, hollow fibers and sponges can be manufactured. Commonly, different follow-up treatments and modifications are applied to improve gel stability and durability. The methods of chitosan gel preparation can be broadly divided into four groups (Hudson and Smith, 1998; Dutta et al., 2002): (i) Solvent evaporation method is mainly used for the preparation of membranes and films. A solution of chitosan in organic acid is cast onto a plate or an electrode tip and allowed to dry, if possible at elevated temperature (ca. $65^{\circ} \mathrm{C}$ ). Upon drying the membrane/film is normally neutralized with a dilute $\mathrm{NaOH}$ solution and cross-linked to avoid disintegration in solutions of $\mathrm{pH}<6.5$. (ii) If an acidic chitosan solution is mixed with alkali, an increase in $\mathrm{pH}$ results in precipitation of solid chitosan. This method is known as neutralization method and is exploited to produce chitosan precipitates, membranes, fibers, but foremost spherical beads of different sizes and porosities. These are obtained by adding a chitosan solution dropwise to a solution of $\mathrm{NaOH}$. Following the preparation, the beads are commonly subjected to crosslinking. (iii) In this method, an acidic chitosan solution is subjected to straightforward crosslinking by mixing with a cross-linking agent, which results in gelling. To obtain gel membranes, the chitosan solution cast on a plate is immersed in a cross-linking bath, and to obtain beads the solution is added dropwise therein. (iv) By virtue of the attraction of oppositely-charged molecules, chitosan, owing to its cationic polyelectrolyte nature, spontaneously forms water-insoluble complexes with anionic polyelectrolytes (Dumitriu and Chornet, 1998). The anionic polyelectrolytes used include alginate, carrageenan, xanthan, various polyphosphates and organic sulfates or enzymes themselves (Wei et al., 2002). The method is known as ionotropic gelation method (or coacervation) and is utilized chiefly for the preparation of gel beads, which is achieved by adding an anionic polyelectrolyte solution dropwise into an acidic chitosan solution.

Applications of Immobilized Enzymes: Areas of present and potential future applications of immobilized enzyme systems other than industrial (shown in the Table 1.1) include: laboratory scale organic synthesis, and analytical and medical applications (Kennedy and Cabral, 1983; Bullock, 1995; van de Velde et al., 2002). Having been shown to be able to catalyze reactions not only in aqueous solutions but also in organic media, enzymes offer great potential for assisting organic synthesis (Carrea and Riva, 2000). They can simplify the chemical procedures by reducing the number of synthetic steps, they can enhance the purity of the products, and most importantly, they can catalyze regio- and stereoselective synthesis giving, otherwise unobtainable compounds with the desired properties.

In analytical applications immobilized enzymes are used chiefly in biosensors (Guilbault, 1983; Srivastava and Kayastha, 2001) and to a lesser extent, in diagnostic test strips (Reddy et al., 2004). Biosensors are constructed by integrating biological sensing systems, e.g. enzyme(s), with transducers. These obtain a chemical signal produced by the interaction of the biological system with an analyte and transduce it into a measurable response. Different kinds of transducers have been employed in biosensors, viz., potentiometric, amperometric, conductometric, thermometric, optical and piezo-electric, most of 
the current research being placed on the first two. Enzymes for the most cases are immobilized either directly on a transducer's working tip or in/on a polymer membrane tightly wrapping it up.

In principle, due to enzyme specificity and sensitivity biosensors can be tailored for nearly any target analyte, and these can be both enzyme substrates and enzyme inhibitors. Advantageously, their determination is performed without special preparation of the sample. Meeting the demand for practical, costeffective and portable analytical devices, enzyme-based biosensors have enormous potential as useful tools in medicine, environmental in situ and real time monitoring, bioprocess and food control, and in biomedical and pharmaceutical analysis. Their use, impaired as yet by not quite satisfactory reliability, is predicted to become widely accepted once their storage and operational stabilities have been improved. From a practical and commercial point of view, four of the sensors, namely glucose, lactate, urea and glutamate have been widely used (Wilson and $\mathrm{Hu}, 2000)$.

Table 1: Important industrial applications of immobilized enzyme systems (Krajewska, 2004)

\begin{tabular}{lll}
\hline Enzyme (EC number) & Substrate & Product \\
\hline Glucose isomerase (5.3.1.5) & Glucose & Fructose (high-fructose corn syrup) \\
B-Galactosidase (3.2.1.23) & Lactose & Glucose and galactose (lactose-free milk and whey) \\
Lipase (3.1.1.3) & Triglycerides & Cocoa butter substitutes \\
Nitrile hydratase (4.2.1.84) & Acrylonitrile & Acrylamide \\
& 3-Cyanopyridine & Nicotinamide \\
Aminoacylase (3.5.1.14) & Adiponitrile & 5-Cyanovaleramide \\
Raffinase (3.2.1.22) & D,L-Aminoacids & L-Amino acids (methionine, alanine, phenylalanine, tryptophan, valine) \\
Invertase (3.2.1.26) & Raffinose & Galactose and sucrose (raffinose-free solutions) \\
Aspartate ammonia-lyase (4.3.1.1) & Sucrose & Glucose/fructose mixture (invert sugar) \\
Thermolysin (3.4.24.27) & Ammonia + fumaric acid & L-Aspartic acid (used for production of synthetic sweetener aspartame) \\
Glucoamylase (3.2.1.3) & Starch & Aspartame \\
Papain (3.4.22.2) & Proteins & D-Glucose \\
Hydantoinase (3.5.2.2) & D,L-Amino acid hydantoins & Removal of "chill haze" in beers \\
Penicillin amidase (3.5.1.11) & Penicillins G and V & D,L-Amino acids \\
B-Tyrosinase (4.1.99.2) & & 6-Aminopenicillanic acid (precursor of semi-synthetic penicillins, \\
\hline
\end{tabular}

Medical applications of immobilized enzymes include (Kennedy and Cabral, 1983; Bullock, 1995) diagnosis and treatment of diseases, among those enzyme replacement therapies, as well as artificial cells and organs, and coating of artificial materials for better biocompatibility. Offering a great potential in this area, real application of immobilized enzymes has as yet suffered from serious problems from their toxicity to the human organism, allergenic and immunological reactions as well as from their limited stability in vivo.

\section{References}

1. Beaton, J.D. (1978). Urea: its popularity grows as a dry source of nitrogen. Crops and Soils, 30: 11-14.

2. Bourdillon, C., Bourgeois, J.P. and Thomas D. (1980). Covalent linkage of glucose oxidase on modified glassy carbon electrodes-kinetic phenomena. Journal of the American Chemical Society, 102: 4231-4235.

3. Bremner, J.M. and Mulvaney R.L. (1978). Urease activity in soils. In: Soil enzymes. (Ed, Burns RG) Academic Press Inc, New York. pp 149-196.

4. Bryant, M.P. (1959). Bacterial species of the rumen. Bacteriological Reviews, 23: 125-153.

5. Bullock, C. (1995). Immobilized enzymes. Science Progress, 78: 119-134.

6. Carlini, C.R. and Guimarães, J.A. (1981). Isolation and characterization of a toxic protein from Canavalia ensiformis (jack bean) seeds, distinct from concanavalin. Toxicon, 19: 667-675. 


\section{Urease: Occurrence, inhibition and immobilization}

7. Carrea, G. and Riva, S. (2000). Properties and synthetic applications of enzymes in organic solvents. Angewandte Chemie International Edition, 39: 2226-2254.

8. Cho, Y.K. and Bailey, J.E. (1977). Enzyme immobilization on activated carbon: alleviation of enzyme deactivation by hydrogen peroxide. Biotechnology and Bioengineering, 19: 769-775.

9. Cho, Y.K., Bailey J.E. (1979). Immobilization of enzymes on activated carbon: selection and preparation of carbon support. Biotechnology and Bioengineering. 21: 461-476.

10. Dixon, N.E., Blakeley, R.L. and Zerner, B. (1980). Jack bean urease (EC 3.5.1.5). III. The involvement of active-site nickel ion in inhibition by $\beta$-mercaptoethanol, phosphoramidate, and fluoride. Canadian Journal of Biochemistry and Physiology, 58: 481-488.

11. Dumitriu, S. and Chornet, E. (1998). Inclusion and release of proteins from polysaccharide-based polyion complexes. Advanced Drug Delivery Reviews, 31: 223-246.

12. Dutta, P.K. and Ravikumar, M.N.V. and Dutta, J. (2002). Chitin and chitosan for versatile applications. Journal of Macromolecular Science, 42: 307-354.

13. Follmer, C. and Carlini, C.R. (2005). Effect of chemical modification of histidines on the copper-induced oligomerization of jack bean urease (EC 3.5.1.5). Archives Biochemistry Biophysics, 435: 15-20.

14. Follmer, C., Barcellos, G.B.S., Zingali, R.B., Machado, O.L.T., Alves, E.W., Barja-Fidalgo, C., Guimaräes, J.A. and Carlini, C.R. (2001). Canatoxin, a toxic protein from jack beans (Canavalia ensiformis), is a variant form of urease (EC 3.5.1.5): biological effects of urease independent of its ureolytic activity. Biochemical Journal, 360: 217-224.

15. Follmer, C., Wassermann, G.E. and Carlini, C.R. (2004). Separation of jack bean (Canavalia ensiformis) urease isoforms by immobilized metal affinity chromatography and characterization of insecticidal properties unrelated to ureolytic activity. Plant Science, 167: 241-246.

16. Gallardo, F., Fu, J., Canton, F.R., GarciaGutierrez, A., Canovas, F.M. and Kirby, E.G. (1999). Expresión of a conifer glutamine synthetase gene in transgenic poplar. Planta, 210: 19-26.

17. Germain, P. and Crichton, R.R. (1980). Characterization of a chemically modified amylase immobilized on porous silica. Journal of Chemical Technology and Biotechnology, 41: 297-315.

18. Gorton, L. (1995). Carbon paste electrodes modified with enzymes, tissues and cells. Electroanalysis, 7: 23-45.

19. Guilbault, G.G. (1983). Immobilized enzyme electrode probes. In: Scouten, W.H. (ed.), Solid Phase Biochemistry: Analytical and synthetic aspects. John Wiley \& Sons, New York. pp 479-505.

20. Hirai, M., Kawai-Hirai, R., Hirai, T. and Ueki, T. (1993) Structural change of jack bean urease induced by addition of surfactants studied with synchrotronradiation small-angle X-ray scattering. European Journal of Biochemistry, 215: 55-61.

21. Hirayama, C., Sugimura, M., Saito, H and Nakamura, M. (2000) Purification and properties of urease from leaf of mulberry, Morus alba. Phytochemistry, 53: 325-330.

22. Hudson, S.M. and Smith, C. (1998). Polysaccharides: chitin and chitosan; chemistry and technology of their use as structural materials. In: Kaplan, D.L. (Ed.) Biopolymers from renewable resources. Berlin Springer. pp 96-118.

23. Hughes, R.B., Katz, S.A. and Stubbins, S.E. (1969). Inhibition of urease by metal ions. Enzymolgia, 36: 332-334.

24. Huntington, C.B. (1986). Uptake and transport of non-protein nitrogen by the 
ruminant gut. Federation proceedings. 45 : 2272-2276.

25. Karmali, A. and Domingos, A. (1993). Monoclonal antibodies against urease from Canavalia ensiformis. Biochimie, 75: 1001-1006.

26. Katz, E., Heleg-Shabtai, V., Willner, B., Willner, I. and Buckmann A.F. (1997). Electrical contact of redox enzymes with electrodes: novel approaches for amperometric biosensors. Bioelectrochemistry and Bioenergetics, 42: 95-104.

27. Kennedy, J.F. and Cabral, J.M.S. (1983). Immobilized enzymes: analytical and synthetic aspects. In: Solid Phase Biochemistry (Ed. Scouten, W.H.) John Wiley \& Sons, New York. pp 253-339.

28. Kokufuta, E., Shimizu, N., Tanaka, H. and lsei, I. (1988). Use of polyelectrolyte complex stabilized calcium alginate gel for entrapment of amylase. Biotechnology Bioengineering, 32: 756-759.

29. Krajewska, B. (2004). Application of chitin- and chitosan-based materials for enzyme immobilizations: a review. Enzyme and Microbial Technology, 35: 126-139.

30. Kumar, S. (2015). Plant Ureases: Physiological Significance, role in Agriculture and Industrial Applications A Review. South Asian Journal of Food Technology and Environment, 1(2): 105115

31. Kumar, S. (2016). Effects of thiols on the activity of soybean (Glycine max) urease. South Asian Journal of Food Technology and Environment, 2(1): 299-303.

32. Kumar, S. and Kayastha A.M. (2010a). Acetohydroxamic acid: a competitive inhibitor of urease from soybean (Glycine max). Journal of Proteins and Proteomics, 1(1): 3-8.

33. Kumar, S. and Kayastha, A.M. (2010b). Inhibition studies of soybean (Glycine max) urease with heavy metals, sodium salts of mineral acids, boric acid and boronic acids. Journal of Enzyme Inhibition and Medicinal Chemistry, 25(5): 646-652.

34. Kumar, S. and Kayastha, A.M. (2010c). Soybean (Glycine max) urease: role of sulfhydryl groups in urea catalysis. Plant Physiology and Biochemistry, 48: 746750.

35. Kumar, S. and Kayastha, A.M. (2012). Studies of Histidine Residues in Soybean (Glycine max) Urease. Protein \& Peptide Letters, 19: 657-660

36. Kumar, S., Dwevedi, A. and Kayastha, A.M. (2009). Immobilization of soybean (Glycine max) urease on alginate and chitosan beads showing improved stability: Analytical applications. Journal of Molecular Catalysis B: Enzymatic,58: 138-145.

37. Kumar, S., Kansal, A. and Kayastha, A.M. (2005). Immobilization of jack bean (Canavalia ensiformis) urease on gelatin and its characterization. Oriental Pharmacy and Experimental Medicine, 5(1): 43-47.

38. Kurita, K. (2001). Controlled functionalization of the polysaccharide chitin. Progress in Polymer Science, 26: 1921-1971.

39. Lehari, K., Kumar, S. and Kumar, P. (2015) Kinetics of thermal inactivation and inhibition studies of pigeonpea urease (Cajanus cajan). South Asian Journal of Food Technology and Environment, 1(3\&4): 242-249.

40. Limami, A., Phillipson, B., Ameziane, R., Pernollet, N., Jiang, Q., Roy, R., Deleens, E., Chaumont-Bonnet, M., Gresshoff, P.M. and Hirel B. (1999). Does root glutamine synthetase control plant biomass production in Lotus japonicus L.? Planta, 209: 495-502.

41. Liu, C.C., Lahoda, E.J., Galasco, R.T. and Wingard, R.B. (1975). Immobilization of lactase on carbon. Biotechnology and Bioengineering, 17: 1695-1696. 
42. Martin, P.R. and Hausinger, R.P. (1992). Site-directed mutagenesis of the active site cysteine in Klebsiella aerogenes urease. Journal of Biological Chemistry, 267: 20024-20027.

43. Masover, G.K., Razin, S. and Hayflick L. (1977b). Localization of enzymes in Ureaplasma urealyticum (T-strain mycoplasma). Journal of Bacteriology, 130: 297-302.

44. Masover, G.K., Razin, S. and Hayflick, L. (1977a). Effects of carbon dioxide, urea, and ammonia on growth of Ureaplasma urealyticum (T-strain mycoplasma). Journal of Bacteriology, 130: 292-296.

45. Merino, P., Estavillo, J.M., Graciolli, L.A., Pinto, M., Lacuesta, M., MunozRueda, A., Gonzalez-Murua, C. (2002). Mitigation of $\mathrm{N}_{2} \mathrm{O}$ emissions from grassland by nitrification inhibitor and Actilith F2 applied with fertilizer and cattle slurry. Soil Use and Management, 18: 135-141.

46. Mobley, H.L., Island, M.D. and Hausinger, R.P. (1995). Molecular biology of microbial ureases. Microbiological Reviews, 59: 451-480.

47. Mobley, H.L.T. and Hausinger, R.P. (1989). Microbial ureases: significance, regulation, and molecular characterization. Microbiological Reviews, 53: 85-108.

48. Obha, R., Shibata, T. and Ueda, S. (1979). Preparation and properties of covalently immobilized $\beta$-amylase from sweet potato on p-aminobenzyl cellulose. Journal of Fermentation Technology, 57: 146-150.

49. Pearson, M.A., Overbye Michel, L., Hausinger, R.P. and Karplus, P.A. (1997). Structures of Cys319 variants and acetohydroxamate-inhibited Klebsiella aerogenes urease. Biochemistry, 36: 81648172.

50. Peter, M.G. (1995). Applications and environmental aspects of chitin and chitosan. Journal of Macromolecular
Science Part A Pure and Applied Chemistry, 32: 629-640.

51. Polacco, J.C. and Holland, M.A. (1993). Roles of urease in plant cells. In: International Review of Cytology (Eds. Jeon KW, Jarvik J) Academic Press, Inc San Diego. Vol. 145 pp 65-103.

52. Polacco, J.C. and Holland, M.A. (1994). Genetic control of plant ureases. In: Genetic Engineering (Ed. Setlow, J.K.) Plenum Press, New York. Vol. 16, pp 3348.

53. Pollack, J. (1986). Metabolic distinctiveness of ureaplasmas. Pediatric Infectious Disease Journal, 5: S305-S307.

54. Ray, R.R., Jana, S.C. and Nanda, G. (1994). Saccharification of indigenous starches by $\beta$-amylase of Bacillus megaterium. Journal of Microbiology and Biotechnology, 10: 691-693.

55. Reddy, K.R.C., Srivastava, P.K., Dey, P.M. and Kayastha, A.M. (2004) Immobilization of pigeonpea (Cajanus cajan) urease on DEAE-cellulose paper strips for urea estimation. Biotechnology and Applied Biochemistry, 39: 323-327.

56. Riddles, P.W., Whan, V, Blakeley, R.L. and Zerner, B. (1991). Cloning and sequencing of a jack bean ureaseencoding cDNA. Gene, 108: 265-267.

57. Romano, N. La Licata, R. and Alesi, D.R. (1986). Energy production in Ureaplasma urealyticum. Pediatric Infectious Disease, 5: S308-S312.

58. Romano, N., Tolone, G., Ajello, F. and La Licata, R. (1980). Adenosin 5'triphosphate sysnthesis induced by urea hydrolysis in Ureaplasma urealyticum. Journal of Bacteriology, 144:830-832.

59. Rosenstein, I.J.M. (1986). Urinary calculi: microbiological and crystallographic studies. Critical Reviews in Clinical Laboratory Sciences, 23: 245-277.

60. Roy, F. and Hedge M.V. (1987). Immobilization of $\beta$-amylase on polystyrene cations exchange resin equilibrated with $\mathrm{Al}^{3+}\left(\mathrm{Ir}-120 \quad \mathrm{Al}^{3+}\right)$. 
Enzyme and Microbial Technology, 9: 550-552.

61. Sheffield, D.J., Harry, T.R., Smith, A.J. and Rogers, L.J. (1995). Corallina officinalis bromoperoxidase immobilized on agarose. Phytochemistry, 38: 11031107.

62. Sirko, A. and Brodzik, R. (2000). Plant ureases: roles and regulation. Acta Biochimica Polonica, 47: 1189-1195.

63. Srivastava, P.K., Kayastha, A.M., and Srinivasan (2001). Characterization of gelatin-immobilized pigeonpea urease and preparation of a new urea biosensor. Biotechnology and Applied Biochemistry, 34: 55-62.

64. Stelly, M. (1980). Nitrification InhibitorsPotentials and Limitations. ASA Special Publication No. 38. American society of Agronomy, Soil Science Society of America, Madison, Wisconsin.

65. Stitt, M. (1999) Nitrate regulation of metabolism and growth. Current Opinion in Plant Biology, 2: 178-186.

66. Swati, M., Kumar, S., Reddy, K.R.S. and Kayastha, A.M. (2007). Immobilization of urease from pigeonpea (Cajanas cajan) on agar tablets and its application in urea assay. Applied Biochemistry and Biotechnology, 142: 291-297.

67. Takishima, K., Suga, T. and Mamiya,G. (1988). The structure of jack bean urease. The complete amino acid sequence, limited proteolysis and reactive cysteine residues. European Journal of Biochemistry, 175: 151-165.

68. Taylor-Robinson, D. and Gourlay, R.N. (1984). Ureaplasma. In: Krieg, N.R., (ed), Bergey's Manual systematic bacetriaology, Vol. I. William and Wilkins, Baltimore. Pp. 770-775.

69. Todd, M.J. and Hausinger, R.P. (1991). Identification of the essential cysteine residue in Klebsiella aerogenes urease. Journal of Biological Chemistry, 266: 24327-24331.
70. van de Velde, F., Lourenço, N.D., Pinheiro, H.M. and Bakker, M. (2002). Carrageenan: a food-grade and biocompatible support for immobilization techniques. Advanced Synthesis \& Catalysis, 344: 815-835.

71. Varner, J.E. (1959). Urease. In: The enzymes. (Eds. Boyer, P.D., Lardner, H. and Myrback, K.) Academic Press Inc, New York. Vol. 4, pp 247-256.

72. Vogels, G. and van der Drift, C. (1976). Degradation of purines and pyrimidines by microorganisms. Bacteriological Reviews, 40: 403-468.

73. Watkins, B.F., Behling, J.R., Kariv, E. and Miller, L.L. (1975). A chiral electrode. Journal of the American Chemical Society, 97: 3549-3550.

74. Wei, X., Cruz, J. and Gorski, W. (2002) Integration of enzymes and electrodes: spectroscopic and electrochemical studies of chitosan-enzyme films. Analytical Chemistry, 74: 5039-5046.

75. Williamson, J.C., Taylor, M.D., Torrens, R.S. and Vojvodic-Vukovic, M. (1998). Reducing nitrogen leaching from dairy farm effluent-irrigated pasture using dicyandiamide: a lysimeter study. Agriculture, Ecosystems \& Environment, 69: 81-88.

76. Wilson, G.S. and Hu, Y. (2000). Enzymebased biosensors for in vivo measurements. Chemical Reviews, 2693704.

77. Wiren, N., Gazzarrini, S., Gojon, A. and, Frommer, W.B. (2000). The molecular physiology of ammonium uptake and retrieval. Current Opinion in Plant Biology, 3: 254-261.

78. Yamaguchi, K., Cosper, N.J., Stalhandske, C., Scott, R.A., Pearson, M.A., Karplus, A. and Hausinger, R.P. (1999). Characterization of metal substituted Klebsiella aerogenes urease. Journal of Biological Inorganic Chemistry, 4: 468-477. 
79. Zhang, L., Mulrooney, S.B., Leung, A.F., Zeng, Y., Ko, B.B., Hausinger, R.P. and Sun, H. (2006), Inhibition of urease by bismuth (III): implications for the mechanism of action of bismuth drugs. Biometals, 19 : 503-511.

Received: July, 2016 